\title{
Effect of the forming process on the microstructure of aluminium parts for collective transports
}

\author{
B. Diawara ${ }^{1,2,3}$, J. Bouquerel ${ }^{2}$, J.-B. Vogt $^{2}$, D. Najjar ${ }^{3}$ and M. Dubar ${ }^{1}$ \\ 1 TEMPo Laboratory, University of Valenciennes, France \\ 2 UMET Laboratory, University of Lille 1, France \\ ${ }^{3}$ LML Laboratory, Ecole Centrale de Lille, France
}

\begin{abstract}
The topic of the current work is an investigation of the microstructure of 6082 Aluminium alloy in artificial aged condition (T6 condition) before and after cold forging test. Aluminium is an essential choice when working on the lightening of metallic structures. Different levels of plastic strain have been applied to correlate the forging parameters with the microstructure changes. EBSD in combination with EDS analysis have been performed to well describe the microstructure properties. It was found that the local misorientation inside the grains increases with the nominal plastic strain. The formation of low angle grain boundaries $\left(2^{\circ}<\theta<15^{\circ}\right)$ takes place both along initial grain boundaries $\left(\theta>15^{\circ}\right)$ and within the original grains. This result is an indication of the local deformation of grains during cold forging.
\end{abstract}

\section{INTRODUCTION}

In automotive industry, looking for lightweight components is a central challenge. Due to economical and ecological reasons as well as to improve product properties, a mass reduction is necessary [1]. Getting mass reduction of the vehicles is closely related to the use of light materials such as Aluminium alloys. The 6082 alloy is well used in automotive components because of its weight reduction, its higher mechanical properties, its excellent corrosion resistance and its good weldability in comparison with other aluminium alloys [2]. However, the high strength of the 6082 alloy limits its formability and requires higher forces in forming operations. That's why before forming some annealing steps at high or moderate temperatures are required to improve the material ductility. But elevating temperature induces deformation and modification of the final product geometry, it is also time consuming and expensive to do such heat treatment. An alternative to avoid these problems is to cold form at room temperature. Many studies have been carried out on 6082 Aluminium cold forming processes. However less work has been accomplished on the effect of the process on the microstructure changes. Indeed, microstructure changes induced by cold forming play a crucial role for mechanical failure and wear of contacting materials. The aim of the present work is to understand the effect of cold forging on the microstructure changes of the 6082 alloy by means of advanced analysis tool such as SEM-EBSD.

\section{EXPERIMENTAL PROCEDURES}

The material used as work-piece is a rolled 6082 Aluminium alloy $(0.92 \% \mathrm{Si}, 0.41 \% \mathrm{Fe}, 0.58 \% \mathrm{Mn}, 0.78 \% \mathrm{Mg}$, $0.04 \% \mathrm{Cr}$ ) in the $\mathrm{T} 6$ condition (annealing at $530{ }^{\circ} \mathrm{C}-1 \mathrm{~h}$, subsequent cooling in the water and artificial ageing at $175^{\circ} \mathrm{C}$ for $10 \mathrm{~h}$ ). Single pass cold forging tests were carried out on the Upsetting Sliding Test machine (UST)
[3], which allows simultaneous compression and friction movements. During the test the indenter moves along the work-piece (Fig. 1). Both normal $\left(\mathrm{F}_{n}\right)$ and tangential $\left(\mathrm{F}_{t}\right)$ forces are recorded so that the mean Coulomb's friction factor can be determined. All tests were performed with a constant velocity of $10 \mathrm{~mm} / \mathrm{s}$ and variable plastic strain of $0.02,0.04,0.06,0.08$ and 0.10 . Two kinds of work-pieces were used during cold forging: dried and lubricated. Contact surfaces of the work-pieces were lubricated with solid spray bisulfide molybdenum $\left(\mathrm{M}_{\mathrm{o}} \mathrm{S}_{2}\right)$ at room temperature. After plastic deformation, edge and center areas of transverse (TD) and normal (ND) crosssections surfaces were investigated by EBSD.

\section{RESULTS AND DISCUSSION}

\subsection{Characterisation of the damage}

SEM micrograph in Figure 2 indicates that strong plastic deformation and surface layers abrasion take place in the deformed specimens. The indenter asperities press strongly the surface layers of Aluminium leading to plastic deformation and localized cracking. This is due to the fact that hardness of the indenter is higher than that of the work-piece. Sliding movement also leads to the formation of tracks showing abrasion by the indenter. For lubricated specimens, the surface damages increase with the nominal plastic strain. A comparison of the surfaces properties was made between lubricated and unlubricated specimens, it can be seen in Figure 2.b and d that for the same nominal plastic strain, there is reduction of the surface abrasion and cracks, by the use of the lubricant. In addition unlubricated specimens exhibit higher value of friction factor than the lubricated ones (Table 1). This observation reflects the fact that friction on dry Aluminium surface causes a lot of adhesion of aluminium onto the indenter to form hard Alumina particles $\left(\mathrm{Al}_{2} \mathrm{O}_{3}\right)$ and those latter contribute to the increase of the friction fractor, scratch and damage. Holes were generally found near the intermetallic particles. 
Table 1. Friction factor of 6082 aluminium with a nominal plastic strain of 0.06 .

\begin{tabular}{|l|c|c|}
\hline & $\begin{array}{c}\text { Unlubricated } \\
\text { specimen }\end{array}$ & $\begin{array}{c}\text { Lubricated } \\
\text { specimen }\end{array}$ \\
\hline Friction factor & 0.48 & 0.06 \\
\hline
\end{tabular}

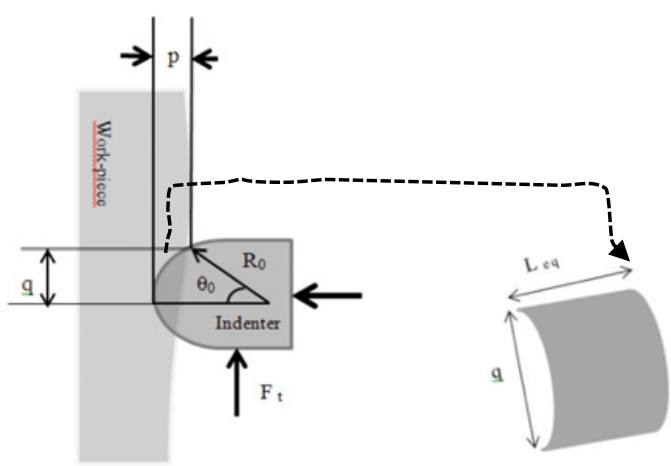

Figure 1. Schematic illustration of the Upsetting Sliding Test [3].

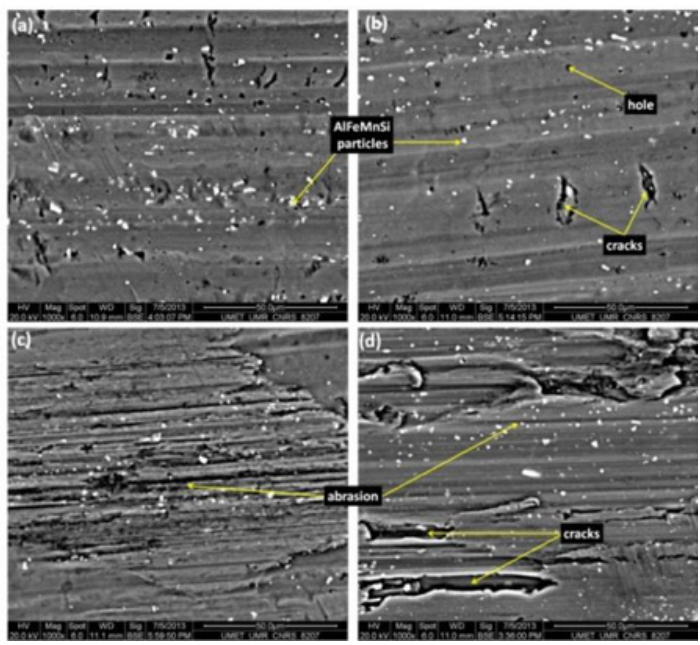

Figure 2. SEM micrographs of 6082 aluminium at different plastic strain: a) $0 \%$; b) lubricated and strained at 0.06 ; c) lubricated and strained at 0.08 ; d) unlubricated and strained at 0.06

This suggests that intermetallic particles can be source of holes which could grow by plastic deformation until final coalescence.

\subsection{In-depth microstructure analysis by SEM-EBSD}

Figure 3 illustrates the evolution of the grain boundaries as a function of the applied plastic strain. The formation of Low Angle Grain Boundaries (LAGB) was mainly observed for the deformed samples and their densities increase with magnitude of the plastic strain. Several authors have reported that intra-granular misorientations are indicative of dislocation structures which have accumulated during deformation. The Kernel Average Misorientation (KAM) [4] distribution of the deformed specimens presented in Figure 4 globally shows a shift to the higher values and provides a large dispersion which

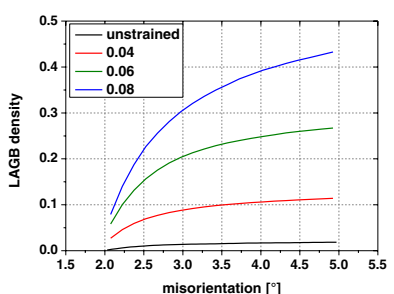

Figure 3. Evolution of the grain boundaries density during cold deformation.

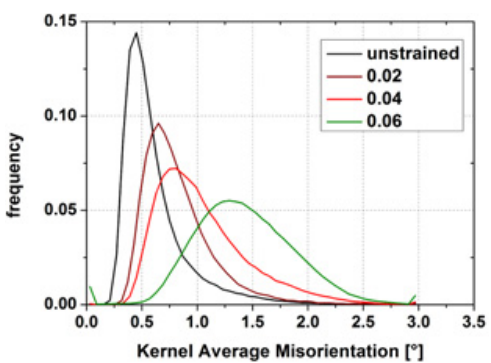

Figure 4. KAM distributions.

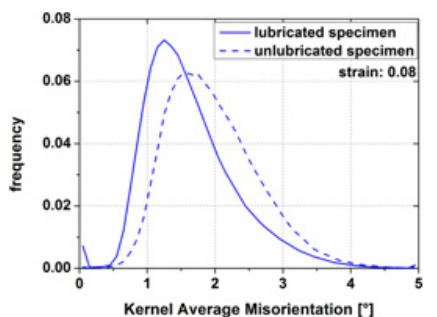

Figure 5. Lubrication effect of the cold forging - KAM ditributions.

corresponds to the widespread of the misorientation. The lubrication effect on the cold forming is also observed. Indeed, KAM values of the unlubricated specimen are higher than those of the lubricated (Fig. 5). This is likely due to the fact that lubrication reduces the friction of the indenter on the specimen.

\section{CONCLUSIONS}

The current work describes the microstructure changes of 6082 Aluminium alloy during cold forging by using different magnitude of plastic strain. The microstructural evolution of the material showed a strong dependency on the applied strain. The increase of the strain affects the local misorientation of the grains as shown through the LAGB and KAM maps obtained by SEM-EBSD. The lubrication effect on the cold forging was also studied. Here, the use of bisulfide molybdenum as lubricant was effective to reduce surface damage and the friction factor. The main surface damages which were observed in the 6082 aluminum alloy were cracks, abrasion, holes, broken particles and plastic deformation.

The present research work has been supported by International Campus on Safety and Intermodality in Transportation (CISIT), 
the Nord-Pas-de-Calais Region, the European Community, the Regional Delegation for Research and Technology, the Ministry of Higher Education and Research, and the National Center for Scientific Research. The authors gratefully acknowledge the support of these institutions.

\section{References}

[1] Jeswiet, J., Geiger, M., Engel, U., Kleiner, M., Schikorra, M., Duflou, J., Neugebauer, R., Bariani, P., 2008, Metal forming progress since 2000, CIRP Journal of Manufacturing Science and Technology 1 (2008) 2-17
[2] Engler O, Hirsch J. Texture control by thermomechanical processing of AA $6 \times x \times$ Al-Mg-Si sheet alloys for automotive applications - a review. Materials Science and Engineering. 2002 . A 336, 249-262.

[3] Dubar, L., Dubois, A., Dubar, M., 2006, Friction and Wear Phenomena in Cold Metal Forming: An Integrated Approach, Proceedings of the Institution of Mechanical Engineers, Part B: Journal of Engineering Manufacture, vol. 220 no. 1 1-10

[4] F. Leaux, J. Bouquerel, J. B. Vogt, F. Palleschi, September 2012, Characterization of fatigue damage by EBSD in a ferritic steel, 16th International Colloquium on Mechanical Fatigue of Metals ICMFM-16, Brno, Czech Republic. 